\title{
WPLYW OBRÓBKI CIEPLNEJ NA WŁAŚCIWOŚCI STALI TYPU MARAGING
}

\begin{abstract}
Celem przeprowadzonych badań było określenie wpływu obróbki cieplnej na właściwości stali maraging o oznaczeniu N18K9M5TPr. Porównano wyniki badań właściwości mechanicznych, fraktograficznych, twardości oraz mikrostruktury materiału w stanie dostawy, po przesycaniu oraz przesycaniu i starzeniu. Wykazano, że obróbką cieplną można sterować parametrami wytrzymałościowymi oraz plastycznymi przez dobór temperatury i czasu poszczególnych etapów przesycania i starzenia.
\end{abstract}

Słowa kluczowe: stal maraging, obróbka cieplna, właściwości mechaniczne, twardość, mikrostruktura

\section{Wprowadzenie}

Stale typu maraging ze względu na swoje właściwości mają zastosowanie jako materiał konstrukcyjny w energetyce i lotnictwie, w przemyśle kolejowym i motoryzacyjnym, a także w technologiach wojskowych, m.in. na elementy luf czy poszycia zbiorników paliwowych rakiet. Mimo wysokiej ceny stale te znalazły swoje miejsce w grupie chętnie wybieranych materiałów konstrukcyjnych do zastosowań specjalnych. Mechanizmy wpływające na właściwości stali typu maraging nie są jeszcze do końca wyjaśnione, a dobór parametrów obróbki cieplnej i mechanicznej definiuje wiele zmiennych.

Stosowaną obróbką cieplną (OC) stali typu maraging jest przesycanie i starzenie (hartowanie i odpuszczanie). Dobór czasu trwania poszczególnych procesów OC wpływa istotnie na mikrostrukturę i właściwości mechaniczne tej grupy stali. Przesycanie przeprowadza się w zakresie temperatur $820 \pm 10^{\circ} \mathrm{C}$, chłodzenie przeważnie odbywa się na powietrzu. Wyraźne umocnienie następuje w wyniku wydzielania się faz międzymetalicznych $w$ trakcie procesu starzenia, a zminimalizowanie udziału azotu, węgla, siarki i fosforu przyczynia się do podwyższenia właściwości plastycznych [1-4]. Proces starzenia, podczas którego wydzielają się

\footnotetext{
${ }^{1}$ Autor do korespondencji/corresponding author: Grzegorz Michta, Akademia Górniczo-Hutnicza, al. Mickiewicza 30, 30-059 Kraków, tel.: 12 6172566, e-mail: gmichta@agh.edu.pl

2 Adam Kruk, prof. AGH, Akademia Górniczo-Hutnicza, e-mail: kruczek@agh.edu.pl
} 
cząstki faz międzymetalicznych, powoduje znaczne utwardzenie i spadek właściwości plastycznych. Końcowy stopień umocnienia jest uzależniony od sumy procesów zwiększających i obniżających umocnienie [2, 4-6]. Odpowiednio przeprowadzona obróbka cieplna stali maraging zapewnia uzyskanie bardzo wysokiej wytrzymałości na rozciąganie $\mathrm{R}_{\mathrm{m}}$, powyżej $2500 \mathrm{MPa}$, wraz z zachowaniem właściwości plastycznych (tj. wydłużenie A w zakresie 7-10\%).

\section{Materiał użyty do badań i obróbka cieplna}

Badaniom zostały poddane próbki wykonane ze stali typu maraging o oznaczeniu N18K9M5TPr (X2NiCoMoTiAl 18-9-5). Ich skład chemiczny zamieszczono w tab. 1. Obróbkę cieplną wykonano na próbkach wyciętych z materiału podstawowego, których kształt był zgodny z normą dotyczącą statycznej próby rozciągania metali PN-EN ISO 6892-1:2016-09. Obróbka cieplna składała się z dwóch etapów, tj. przesycania i starzenia, przy czym badaniom poddano materiał w trzech wariantach:

a) próbki nr 1 nie zostały poddane obróbce cieplnej, zostały pozostawione w stanie dostawy,

b) próbki nr 2 zostały poddane przesycaniu,

c) próbki nr 3 zostały poddane przesycaniu, a następnie starzeniu.

Tabela 1. Skład chemiczny stali N18K9M5TPr

Table 1. Chemical composition of N18K9M5TPr steel

\begin{tabular}{|c|c|c|c|c|c|c|c|c|c|c|c|}
\hline \multirow{2}{*}{$\begin{array}{c}\text { Oznaczenie } \\
\text { stali }\end{array}$} & \multicolumn{10}{|c|}{ Skład chemiczny w \% wag. (reszta Fe) } \\
\cline { 2 - 10 } & $\mathrm{C}$ & $\mathrm{Ni}$ & $\mathrm{Mo}$ & $\mathrm{Co}$ & $\mathrm{Ti}$ & $\mathrm{Al}$ & $\mathrm{Mn}$ & $\mathrm{Si}$ & $\mathrm{S}$ & $\mathrm{P}$ & $\mathrm{N}_{2}$ \\
\hline N18K9M5TPr & 0,03 & $17,5-18,5$ & $4,6-5,0$ & $8,8-9,5$ & $0,5-0,8$ & $0,05-0,18$ & 0,1 & 0,1 & 0,01 & 0,01 & 0,01 \\
\hline Zawartość: $\mathrm{P} \leq 0,01 \% ; \mathrm{S} \leq 0,01 \% ; \mathrm{O} \leq 0,01 \% ; \mathrm{N} \leq 0,01 \% ; \mathrm{Mn} \leq 0,1 \% ; \mathrm{Si} \leq 0,1 \% ; \mathrm{Cu} \leq 0,1 \%$ \\
\hline
\end{tabular}

Przesycanie wykonano $\mathrm{z}$ temperatury $810^{\circ} \mathrm{C}$, a starzenie przeprowadzono przy temperaturze $460^{\circ} \mathrm{C}$. Czas obróbki cieplnej obejmował czas wygrzewania, czyli osiągnięcia założonej temperatury austenityzowania czy starzenia, liczony od momentu jej stabilizacji i został tak dobrany, aby uzyskać optymalne mikrostruktury próbek przy danych temperaturach. Na rysunku 1. pokazano obliczony w programie Thermo-Calc równowagowy układ fazowy badanego stopu, na podstawie którego należy przypuszczać, że w temperaturze starzenia badanego stopu, wynoszącej $460^{\circ} \mathrm{C}$, w warunkach równowagowych będą się znajdować następujące fazy: ferryt, austenit, fazy międzymetaliczne $\mathrm{Mu}$ i $\mathrm{Ni}_{3} \mathrm{Ti}$ oraz niewielka ilość węglików typu $\mathrm{M}_{6} \mathrm{C}$. 


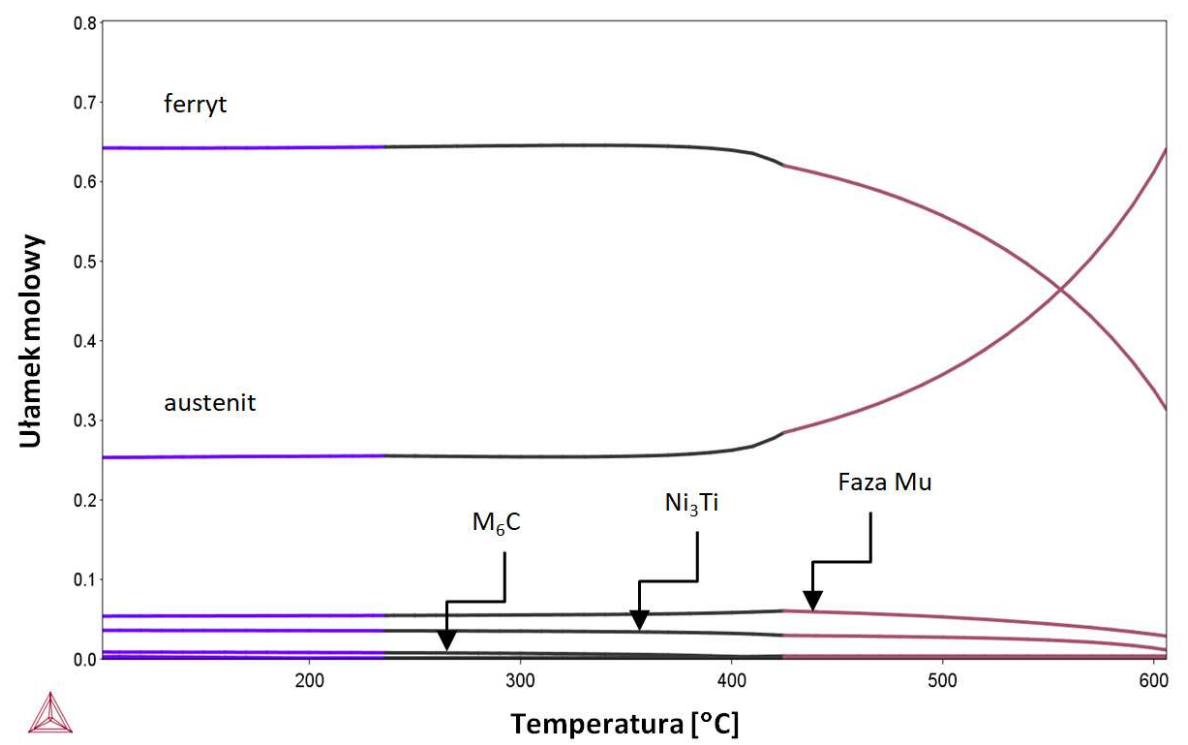

Rys. 1. Obliczony w programie Thermo-Calc równowagowy udział faz w stali maraging N18K9M5TPr występujących przy różnych temperaturach

Fig. 1. The equilibrium phase composition diagram for N18K9M5TPr maraging steel, calculated for different temperatures using the Thermo-Calc program

\section{Wyniki badań}

Statyczna próba rozciągania została wykonana zgodnie $\mathrm{z}$ obowiązującą normą PN-EN ISO 6892-1:2016-09 przy użyciu maszyny wytrzymałościowej MTS 810. Wyniki badań zamieszczone w tab. 2. są średnią z trzech pomiarów. Krzywe rozciągania z poszczególnych wariantów badanych próbek przedstawiono na rys. 2.

Tabela 2. Wyniki badań właściwości mechanicznych

Table 2. Results of mechanical properties tests

\begin{tabular}{|c|c|c|c|c|}
\hline Nr próbki & $\mathrm{Rp}_{0,2}[\mathrm{MPa}]$ & $\mathrm{Rm}[\mathrm{MPa}]$ & $\mathrm{A}[\%]$ & $\mathrm{Z}[\%]$ \\
\hline 1 & 1050 & 1162 & 6,8 & 43,1 \\
\hline 2 & 850 & 1068 & 7,6 & 49,0 \\
\hline 3 & 1800 & 2021 & 5,2 & 22,7 \\
\hline
\end{tabular}




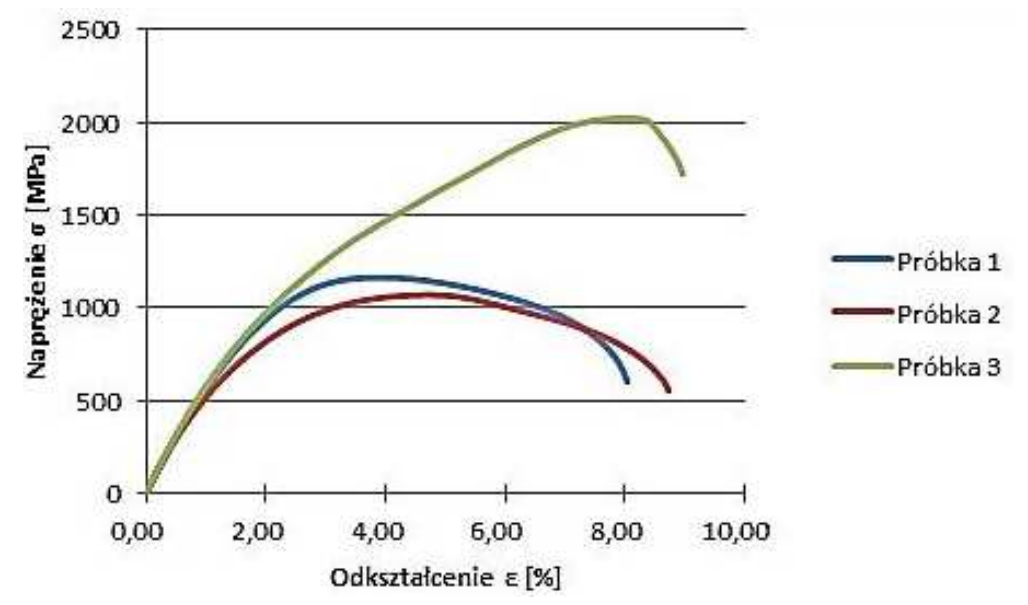

Rys. 2. Przykładowe krzywe rozciągania dla próbek po różnych obróbkach cieplnych

Fig. 2. Examples of stress-strain curves for samples after different heat treatments

Badania twardości przeprowadzono metodą Rockwella według normy PN-EN ISO 6508-1:2016-10. Wycięte próbki poddano szlifowaniu, które usunęło skutki obróbki cieplnej w postaci utlenionej powierzchni. Po wykonaniu trzech pomiarów dla każdej próbki wartość twardości uśredniono i zaokrąglono. Twardość materiału wyjściowego wyniosła $38 \mathrm{HRC}$, materiału po przesycaniu $32 \mathrm{HRC}$, po przesycaniu i starzeniu $56 \mathrm{HRC}$.

Z każdej próbki po różnych wariantach obróbki cieplnej oraz w stanie dostawy wycięto fragmenty, na których przeprowadzono badania mikrostrukturalne na mikroskopie świetlnym Axio Imager M1m firmy ZEISS oraz skaningowym mikroskopie elektronowym Merlin Gemini II firmy ZEISS. Próbki te zatopiono w żywicy przewodzącej i wykonano zgłady metalograficzne. W przypadku obserwacji prowadzonych przy użyciu mikroskopu świetlnego zastosowano obserwacje zarówno w jasnym polu widzenia, jak i w kontraście Nomarskiego. Zgłady metalograficzne były trawione odczynnikiem Kallinga. Mikrostruktury pokazane na rys. 3. charakteryzują się strukturą jednorodną o wydłużonym ziarnie, powstałym podczas przeróbki plastycznej przeprowadzonej w procesie produkcyjnym. Oznacza to, że dostarczony materiał był w stanie odkształconym. Mikrostruktury pokazane na rys. 4. charakteryzują się strukturą jednorodną o drobnym, równomiernym kształcie ziarna. Jest to spowodowane procesem obróbki cieplnej, tj. austenityzowaniem przy temperaturze $810^{\circ} \mathrm{C}$. Obróbka cieplna spowodowała usunięcie skutków odkształcenia obserwowanego w materiale w stanie dostawy. Mikrostruktury przedstawione na rys. 5. charakteryzują się strukturą jednorodną o drobnym, równomiernym kształcie ziarna, które powstało podczas austenityzowania. Na rysunkach 6-8 pokazano mikrostruktury wykonane przy użyciu SEM. 

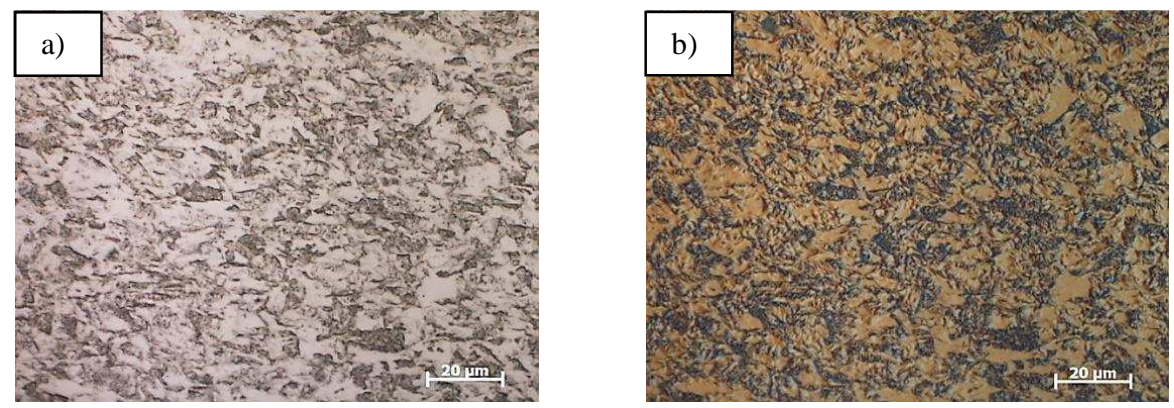

Rys. 3. Przykładowe mikrostruktury stali maraging N18K9M5TPr w stanie dostawy, mikroskop świetlny: a) jasne pole widzenia, b) kontrast Nomarskiego C-DIC

Fig. 3. Examples of N18K9M5TPr maraging steel microstructures in the delivery condition, light microscope: a) bright field of view, b) Nomarski contrast C-DIC
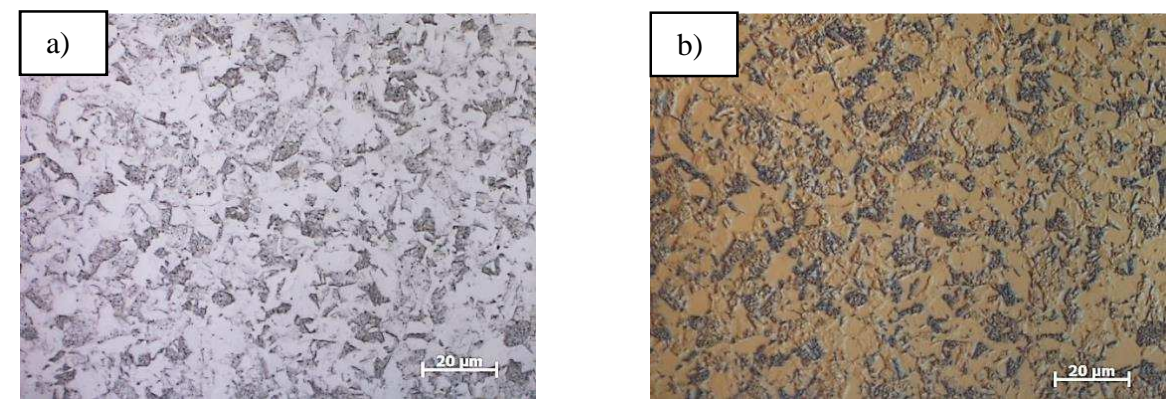

Rys. 4. Przykładowe mikrostruktury stali maraging N18K9M5TPr w stanie przesyconym, mikroskop świetlny: a) jasne pole widzenia, b) kontrast Nomarskiego C-DIC

Fig. 4. Examples of N18K9M5TPr maraging steel microstructures in the delivery condition, light microscope: a) bright field of view, b) Nomarski contrast C-DIC
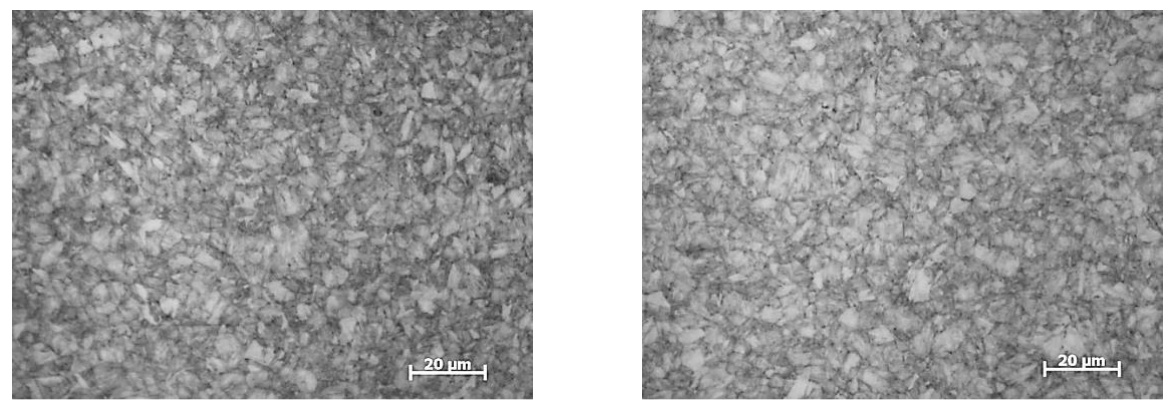

Rys. 5. Przykładowe mikrostruktury stali maraging N18K9M5TPr w stanie przesyconym i starzonym, mikroskop świetlny, jasne pole widzenia

Fig. 5. The exemplary microstructure of N18K9M5TPr maraging steel in quenched and aged state, light microscope, bright field of view 

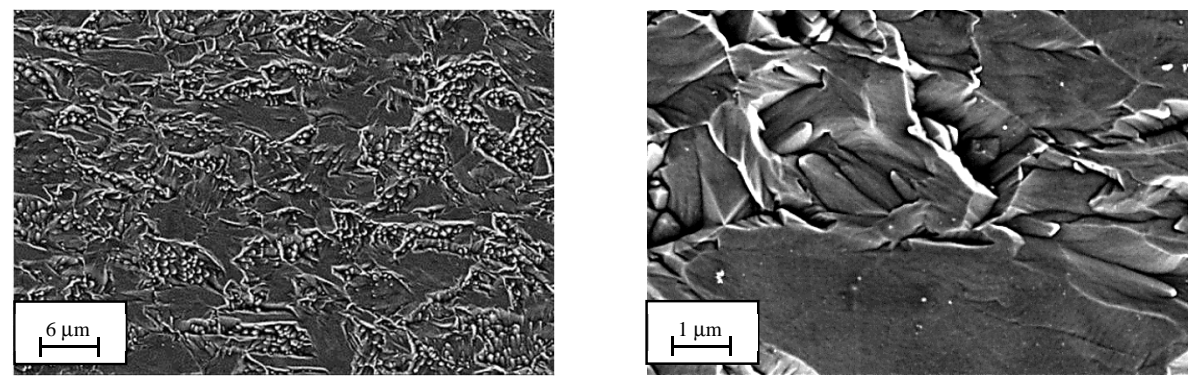

Rys. 6. Przykładowe mikrostruktury stali maraging N18K9M5TPr wykonane przy użyciu skaningowego mikroskopu elektronowego SEM, stan dostawy

Fig. 6. Exemplary microstructures of N18K9M5TPr maraging steel made using a SEM scanning electron microscope, delivery state
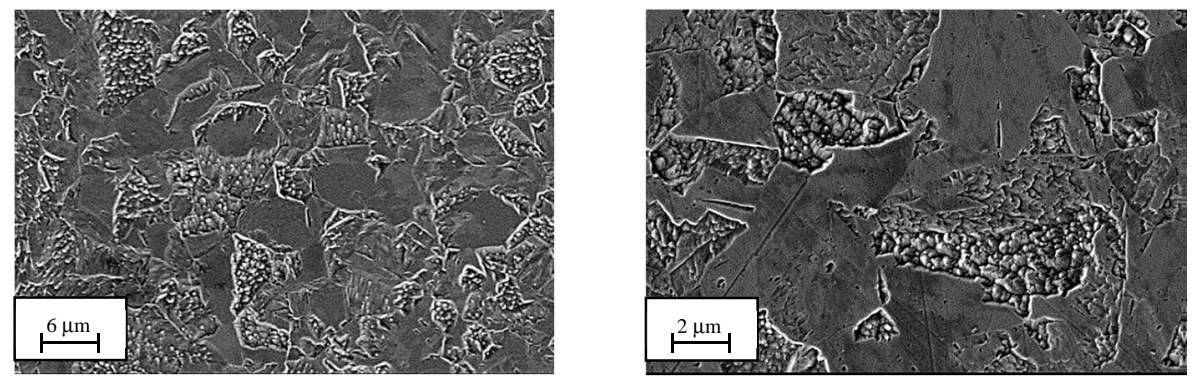

Rys. 7. Przykładowe mikrostruktury stali maraging N18K9M5TPr wykonane przy użyciu skaningowego mikroskopu elektronowego SEM, stan po przesycaniu

Fig. 7. Exemplary microstructures of N18K9M5TPr maraging steel made using a SEM scanning electron microscope, state after quenching
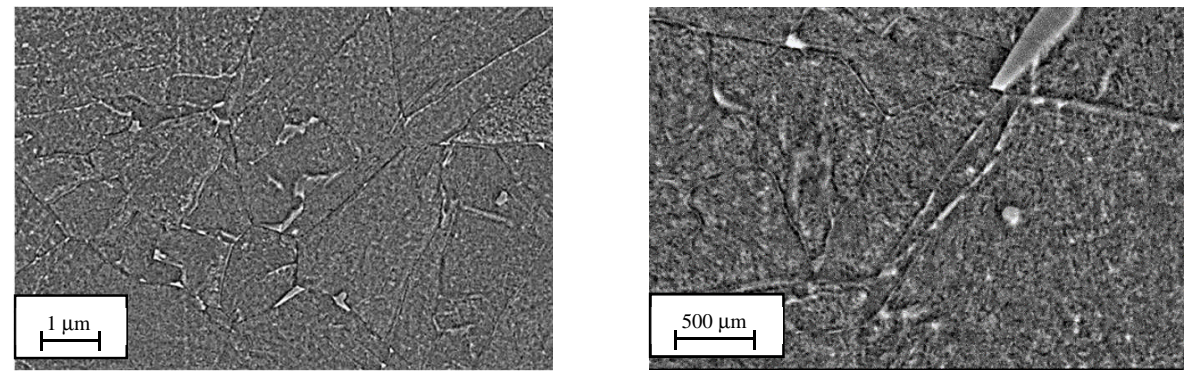

Rys. 8. Przykładowe mikrostruktury wykonane przy użyciu skaningowego mikroskopu elektronowego SEM, stan po przesycaniu i starzeniu

Fig. 8. Exemplary microstructures of N18K9M5TPr maraging steel performed using a SEM scanning electron microscope, state after quenching and aging

Badania wykonane z zastosowaniem skaningowego mikroskopu elektronowego potwierdziły badania wykonane przy użyciu mikroskopu świetlnego. 
Materiał w stanie dostawy wykazał wydłużone ziarno (rys. 6.), a po wykonaniu przesycenia ziarno miało bardziej regularny kształt, na co wpłynęły temperatura i czas austenityzowania (rys. 7.). Materiał poddany przesycaniu i starzeniu charakteryzował się dużą ilością bardzo drobnych wydzieleń powstałych w całej objętości obrobionej cieplnie stali (rys. 8.). Zaobserwować można także większe wydzielenia na granicach ziaren byłego austenitu. Biorąc pod uwagę wykres fazowy w stanie równowagowym (rys. 1.), można przypuszczać, że wydzielenia obserwowane po granicach ziaren byłego austenitu to węgliki typu $\mathrm{M}_{6} \mathrm{C}$, a bardzo drobne wydzielenia obserwowane $\mathrm{w}$ objętości materiału to najprawdopodobniej fazy międzymetaliczne $\mathrm{Mu}$ oraz $\mathrm{Ni}_{3} \mathrm{Ti}$. W celu rzeczywistego określenia składu fazowego powstałych wydzieleń należy wykonać kolejne badania, np. przy użyciu transmisyjnego mikroskopu elektronowego TEM, co nie było celem niniejszej pracy.

Po wykonaniu statycznej próby rozciągania powstałe przełomy poddano obserwacji przy użyciu skaningowego mikroskopu elektronowego. Na rysunku 9. pokazano przełom, jaki powstał po przeprowadzeniu statycznej próby rozciągania w próbce w stanie dostawy. Obserwowane przewężenie świadczy o znacznej plastyczności tego typu stali przy zachowaniu wysokich właściwości wytrzymałościowych, co jest cechą dość rzadką, gdyż zazwyczaj przy wysokich właściwościach wytrzymałościowych właściwości plastyczne są niewielkie. Przełom cechuje się charakterystycznymi dołeczkami (czaszami) występującymi w przełomach plastycznych.
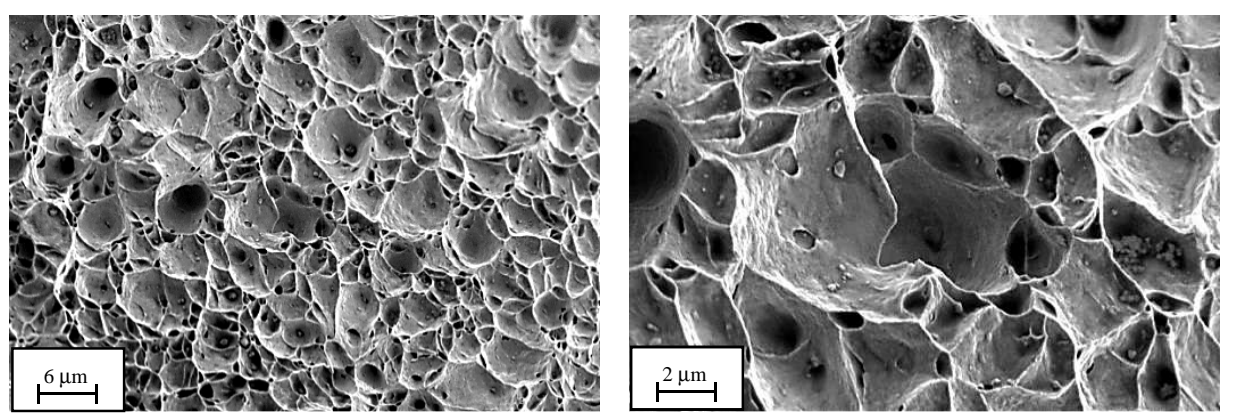

Rys. 9. Przełom stali maraging N18K9M5TPr w stanie dostawy, skaningowy mikroskop elektronowy SEM

Fig. 9. Fracture in N18K9M5TPr maraging steel in delivery condition, scanning electron microscope, SEM

Na rysunku 10. pokazano przełom, jaki powstał w próbce w stanie przesyconym po wykonaniu badań właściwości mechanicznych. Występujące przewężenie świadczy o znacznej plastyczności, co jest cechą charakterystyczną materiałów po przesycaniu. Przełom podobnie jak w stali w stanie dostarczonym cechuje się charakterystycznymi dołeczkami, co świadczy o przełomie plastycznym. 

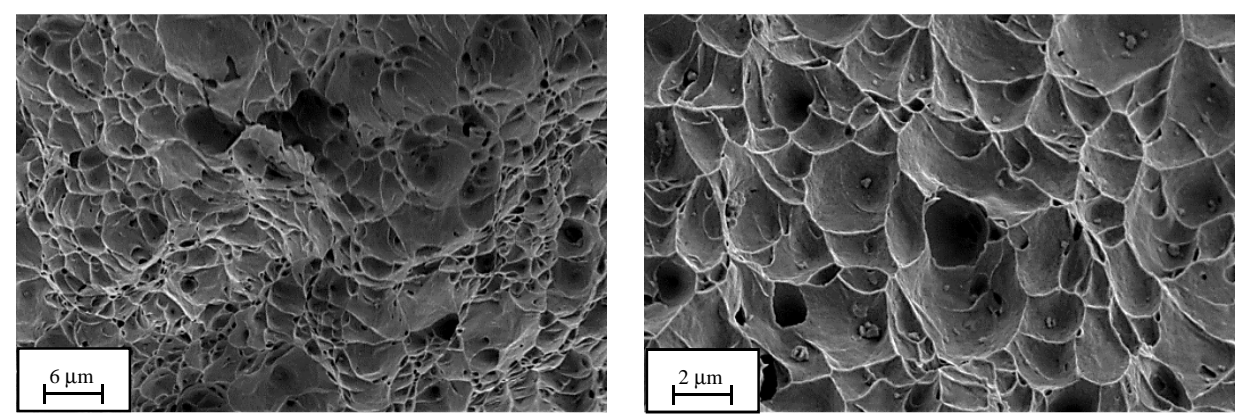

Rys. 10. Przełom stali maraging N18K9M5TPr w stanie przesyconym, skaningowy mikroskop elektronowy SEM

Fig. 10. Fracture in N18K9M5TPr maraging steel after quenching condition, scanning electron microscope, SEM
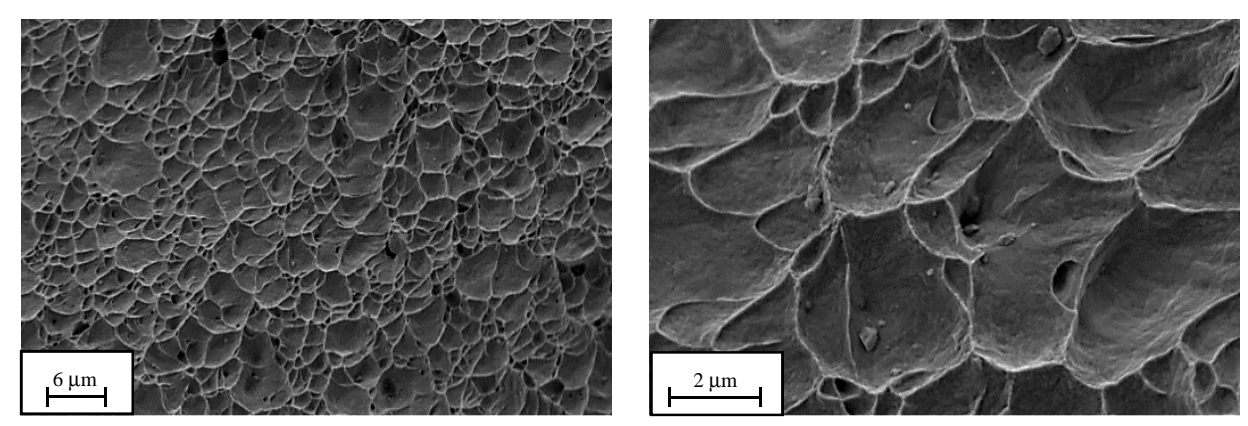

Rys. 11. Przełom stali maraging N18K9M5TPr w stanie po przesycaniu i starzeniu, skaningowy mikroskop elektronowy SEM

Fig. 11. Fracture in N18K9M5TPr maraging steel after quenching and aging condition, scanning electron microscope, SEM

Próbka poddana przesycaniu i starzeniu (rys. 11.) także pękła plastycznie. Powstałe czasze są jednak płytsze, a ich brzegi znacznie mniej wyciągnięte w kierunku rozciągania. Zaobserwować można także regularne kształty i podobne wymiary czasz. Może to wskazywać na powstanie podczas starzenia dużej ilości bardzo drobnych wydzieleń, jednorodnie rozmieszczonych w objętości stali.

\section{Wnioski}

Dzięki przeprowadzonej obróbce cieplnej stali N18K9M5TPr i analizie wyników badań wyciągnięto następujące wnioski:

1. Zgodnie z przewidywaniami, dzięki poszczególnym stopniom obróbki cieplnej właściwości plastyczne stali typu maraging uległy zmianie. Próbki poddane przesycaniu i starzeniu wykazały wzrost właściwości wytrzymałościowych w porównaniu z materiałem przesyconym. 
2. Obróbka cieplna wpływa znacząco na twardość stali typu maraging. Najmniejszą twardość miała próbka nr 2, co jest charakterystyczne dla stali w stanie przesyconym. Z kolei największą twardość wykazała próbka nr 3, poddana przesycaniu i starzeniu, co potwierdziło założenia związane z obróbką cieplną tego stopu, czyli powstanie dużej ilości bardzo drobnych wydzieleń faz międzymetalicznych umacniających badaną stal.

3. Stal N18K9M5TPr w stanie przesyconym i starzonym, mimo bardzo dużej twardości (56 HRC) charakteryzuje się dość wysoką ciągliwością (odkształcenie ok. 5,2\%).

4. Obserwacja przełomów pozwala stwierdzić, że w materiale w każdym stanie obróbki cieplnej występują charakterystyczne dołeczki, co świadczy o powstaniu przełomów plastycznych.

5. Obróbką cieplną można zmieniać właściwości stali maraging w dużym zakresie wartości. W zależności od oczekiwań można sterować właściwościami wytrzymałościowymi oraz plastycznymi przez dobór temperatur oraz czasów poszczególnych etapów przesycania i starzenia.

\section{Literatura}

[1] Chodorowski J., Cieszewski A., Radomski T.: Stale martenzytyczne utwardzane wydzieleniowo (maraging), Hutnik, 6 (1974) 25-28.

[2] Stępień J.: Technologiczne i użytkowe charakterystyki stali przeznaczonych na korpusy silników rakietowych, Instytut Metalurgii Żelaza, Gliwice 2013.

[3] Jeleńkowski J.: Sposób wytwarzania wysoko wytrzymałościowej stali stopowej i stal stopowa, Politechnika Warszawska, Warszawa 1999.

[4] Blicharski M.: Inżynieria materiałowa. Stal, WNT, Warszawa 2010.

[5] Staub F., Adamczyk J., Cieślakowa Ł., Gubała J., Maciejny A.: Metaloznawstwo, Śląskie Wydawnictwo Techniczne, Katowice 1994.

[6] Wójtowicz W., Stępień J., Marcisz J.: Zastosowanie w zakładach metalowych MESKO nowoczesnych stali w wyrobach spełniających standardy NATO, Prace Instytutu Metalurgii Żelaza, Gliwice 2010.

\section{Podziękowania}

Praca zrealizowana w ramach prac statutowych AGH nr 11.11.110. 299 i wykonana dzięki wsparciu badawczemu Międzynarodowego Centrum Mikroskopii Elektronowej dla Inżynierii Materiałowej IC-EM, Akademia Górniczo-Hutnicza im. Stanisława Staszica w Krakowie.

\section{THE INFLUENCE OF HEAT TREATMENT ON MARAGING STEEL PROPERTIES}

\section{S u m m a r y}

As expected, samples of maraging steel subjected to quenching and aging showed the highest increase in strength properties in comparison to the material supplied after hardening. Heat treatment significantly influences hardness of the maraging steel. The highest hardness was demonstrated in 
sample 3, subjected to quenching and aging, which confirmed the assumptions related to the heat treatment of this alloy, i.e. the creation of a large number of very fine precipitates of intermetallic phases reinforcing the tested steel. The N18K9M5TPr steel, in a quenched and aged condition, despite very high hardness ( $56 \mathrm{HRC}$ ), is characterized by quite high toughness (deformation about $5.2 \%$ ). Observation of the fractures of samples after a tensile test allows to observe that for materials with different variants of heat treatment, characteristic dimples are observed in the fractures which indicates plasticity of the fracture.

Keywords: maraging steel, mechanical properties, quenching, aging

DOI: $10.7862 / \mathrm{rm} .2018 .30$

Przestano do redakcji: 23.04 .2018

Przyjęto do druku: 20.06.2018 